\title{
Isolation and characterization of microsatellite loci from the invasive delicate skink (Lampropholis delicata), with cross-amplification in other Australian Eugongylus group species
}

\author{
David G. Chapple • Michael B. Thompson
}

Received: 31 March 2009/Accepted: 1 April 2009/Published online: 19 May 2009

(C) Springer Science+Business Media B.V. 2009

\begin{abstract}
The delicate skink (Lampropholis delicata), native to eastern Australia, is one of the most successful invasive reptiles in the Pacific region, with established populations in New Zealand, the Hawaiian Islands, and Lord Howe Island. Here we isolate and characterize 12 polymorphic microsatellite loci for $L$. delicata. Genetic variation was assessed in individuals from Sydney and also from the eastern Victoria and Tasmanian region. The number of alleles per locus ranged from 2 to 23, with high levels of heterozygosity. All microsatellite loci successfully amplified in individuals from the three invasive populations. Cross-amplification of these loci was assessed in 14 species from other Eugongylus group skink genera. These microsatellite markers will be used to investigate the invasion dynamics of $L$. delicata.
\end{abstract}

Keywords Hawaii - Invasive species .

Lord Howe Island · New Zealand · Microsatellites .

Plague skink · Rainbow skink

D. G. Chapple ( $($ )

Division of Sciences, Herpetology Section, Museum Victoria, GPO Box 666, Melbourne, VIC 3001, Australia

e-mail: dchapple@museum.vic.gov.au

D. G. Chapple

Allan Wilson Centre for Molecular Ecology and Evolution, School of Biological Sciences, Victoria University of Wellington, PO Box 600, Wellington 6140, New Zealand

M. B. Thompson

School of Biological Sciences (A08), University of Sydney,

The Heydon-Laurence Building A08, Sydney,

NSW 2006, Australia
The delicate skink (Lampropholis delicata), known as the rainbow or plague skink in its introduced range, is one of the most successful invasive reptiles in the Pacific region (Lever 2003). It is native to eastern Australia (Wilson and Swan 2008), but is an invasive species in New Zealand, the Hawaiian Islands, and Lord Howe Island (Baker 1979; Lever 2003; Peace 2004; Hutchinson et al. 2005). Lampropholis delicata occurs in extremely high population densities across its introduced range and has the potential to have adverse impacts on the native herpetofauna of New Zealand and Lord Howe Island (Lever 2003; Peace 2004; Hutchinson et al. 2005). We developed 12 microsatellite markers to investigate the invasion dynamics of $L$. delicata.

Total genomic DNA was extracted from the liver of a L. delicata, collected from the grounds of the University of Sydney, Australia, using a Qiagen DNeasy Blood and Tissue Kit as per the manufacturer's instructions (Qiagen Pty Ltd, Melbourne, Australia). Microsatellite DNA library construction, enrichment and screening were completed as per the protocol contained in Jones et al. (2002). Genomic DNA was partially restricted with a cocktail of seven bluntend cutting enzymes (RsaI, HaeIII, Bsr B1, PvuII, StuI, ScaI, Eco RV). Fragments in the size range of 300-750 bp were adapted and subjected to magnetic bead capture (CPG Inc., Lincoln Park, New Jersey, USA), using biotinylated capture molecules.

Libraries were prepared in parallel using Biotin$(\mathrm{AAC})_{12}$, Biotin-(ATG) $)_{12}$, Biotin-(CATC $)_{8}$, and Biotin$(\text { TAGA })_{8}$ as capture molecules in a protocol provided by the manufacturer. Captured molecules were amplified and restricted with HindIII to remove the adapters. The resulting fragments were ligated into the HindIII site of pUC19. Recombinant molecules were electroporated into Escherichia coli $\mathrm{DH} 5 \alpha$ (ElectoMax ${ }^{\mathrm{TM}}$, Invitrogen). One hundred and thirty-two recombinant clones, identified by blue-white 


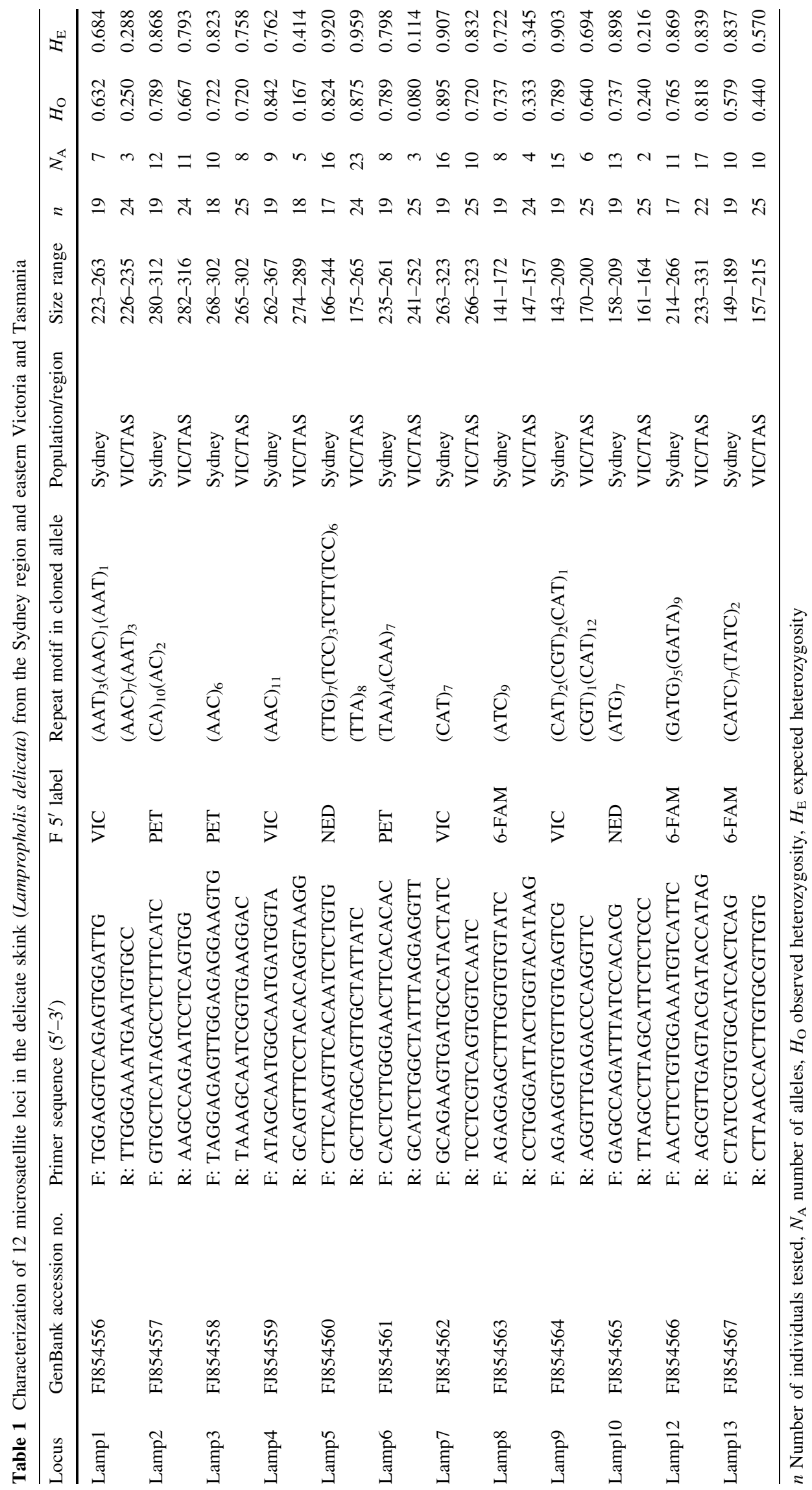


selection, were selected at random for sequencing, and enrichment levels were expressed as the fraction of sequences that contained a microsatellite. Sequences were obtained on an ABI 377 automated sequencer (Applied Biosystems Inc.), using ABI Prism Taq dye terminator cycle sequencing methodology.

Primer pairs were designed from 78 of the 99 microsatellite containing sequences using DESIGNERPCR version 1.03 (Research Genetics Inc). Seven samples from across the native range of $L$. delicata were selected to screen the markers for polymorphism. Twenty-four of the best loci were amplified in $10 \mu \mathrm{l}$ volumes containing the following components: $1 \times$ Biolase Buffer (from $10 \times$ stock supplied by the manufacturer), $2 \mathrm{mM} \mathrm{MgCl} 2,0.2 \mathrm{mM}$ each dNTP, $0.6 \mu \mathrm{M}$ each primer, $0.025 \mathrm{U} / \mu \mathrm{l}$ Biolase Taq polymerase (BioExpress, UK), and $0.2 \mathrm{ng} / \mu \mathrm{l}$ of template DNA. Samples were amplified in a Perkin-Elmer-Cetus thermal cycler by an initial $3 \mathrm{~min}$ denaturation at $94^{\circ} \mathrm{C}$, followed by 35 cycles of denaturation $\left(94^{\circ} \mathrm{C}, 40 \mathrm{~s}\right)$, annealing $\left(55^{\circ} \mathrm{C}\right.$, $40 \mathrm{~s})$, and extension $\left(72^{\circ} \mathrm{C}, 30 \mathrm{~s}\right)$, with final extension time of $4 \mathrm{~min}$ at $72^{\circ} \mathrm{C}$. The PCR products were run on agarose gels to test for amplification and polymorphism. Seventeen microsatellite loci were polymorphic in the seven L. delicata samples.

The polymorphic loci were then characterized in 19 individuals from the Sydney region. Since there is substantial phylogeographic structure present within $L$. delicata (5-8\% mitochondrial sequence divergence among the major genetic lineages; our unpublished data), we also assessed the level of genetic variation in these loci in 25 individuals from eastern Victoria and Tasmania (a region that represents a single phylogeographic lineage within $L$. delicata; our unpublished data). PCR was performed with fluorescently labelled forward primers (see Table 1) on a PTC-225 DNA Engine Tetrad ${ }^{\mathrm{TM}}$ cycler (MJ Research), and multiplexed PCR products were run on an Applied Biosystems ABI3730 DNA analyser with LIZ-500 size standard. The output was analysed with GenemapPer 3.7 (Applied Biosciences). Five loci were excluded from further analysis due to difficulties with amplification, repeat structure or scoring. Observed and expected heterozygosity, deviation from Hardy-Weinberg equilibrium (HWE), and likelihood of linkage disequilibrium (LD) were calculated in GenAlEx 6.2 (Peakall and Smouse 2006) and GENEPOP 4.0 (Rousset 2008). The loci exhibited high levels of polymorphism with the number of alleles ranging from 7 to 16 in the Sydney population and 2-23 in the Victoria-Tasmania region (Table 1). The observed heterozygosity was high (Sydney: 0.579-0.895, Victoria-Tasmania: 0.080-0.875), and the level of genetic variation was generally greater in the Sydney population than in the Victoria-Tasmania region (Table 1). There was no significant deviation from HWE in any of the loci following Bonferroni adjustment for multiple tests, except for
Table 2 Cross-amplification of the 12 microsatellite loci in 14 Australian Eugongylus group skink species

\begin{tabular}{|c|c|c|c|c|c|c|c|c|c|c|c|c|}
\hline \multirow[t]{2}{*}{ Species } & \multicolumn{12}{|c|}{ Lamp loci } \\
\hline & 1 & 2 & 3 & 4 & 5 & 6 & 7 & 8 & 9 & 10 & 12 & 13 \\
\hline $\begin{array}{c}\text { Acritoscincus } \\
\text { duperreyi }\end{array}$ & O & ○ & $\bigcirc$ & $\bigcirc$ & $\bigcirc$ & $\bullet$ & $\bigcirc$ & $\bigcirc$ & $\bigcirc$ & $\diamond$ & $\diamond$ & 0 \\
\hline Anepischtos maccoyi & ○ & ○ & ○ & - & $\bigcirc$ & $\bigcirc$ & $\bullet$ & $\bullet$ & ○ & ○ & $\bigcirc$ & 0 \\
\hline Carlia rubrigularis & O & $\bigcirc$ & $\diamond$ & $\bigcirc$ & $\bigcirc$ & $\bigcirc$ & $\bullet$ & $\bullet$ & 0 & $\bigcirc$ & $\bigcirc$ & $\bullet$ \\
\hline $\begin{array}{l}\text { Cryptoblepharus } \\
\text { carnabyi }\end{array}$ & $\bigcirc$ & $\bigcirc$ & $\diamond$ & $\bigcirc$ & $\bigcirc$ & $\bigcirc$ & 0 & $\bigcirc$ & $\bullet$ & $\bullet$ & $\bigcirc$ & $\bigcirc$ \\
\hline $\begin{array}{l}\text { Eroticoscincus } \\
\text { graciloides }\end{array}$ & $\bigcirc$ & O & $\bullet$ & $\bigcirc$ & O & $\bigcirc$ & O & $\bullet$ & $\bigcirc$ & ○ & $\bigcirc$ & $\bigcirc$ \\
\hline Harrisoniascincus zia & O & O & $\bigcirc$ & $\bigcirc$ & $\bigcirc$ & O & O & O & ○ & ○ & $\bigcirc$ & 0 \\
\hline $\begin{array}{l}\text { Lampropholis } \\
\text { guichenoti }\end{array}$ & $\bigcirc$ & O & $\bigcirc$ & $\bigcirc$ & $\bigcirc$ & O & O & $\bullet$ & ○ & - & $\bigcirc$ & 0 \\
\hline Lygisaurus foliorum & $\bigcirc$ & $\bigcirc$ & $\diamond$ & $\bigcirc$ & $\bigcirc$ & 0 & $\bullet$ & ○ & $\bigcirc$ & ○ & ○ & 0 \\
\hline Menetia greyii & $\bigcirc$ & O & $\bigcirc$ & ○ & $\bigcirc$ & $\bigcirc$ & $\bullet$ & $\bullet$ & 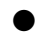 & ○ & $\bigcirc$ & 0 \\
\hline Morethia boulengeri & O & O & $\bigcirc$ & $\bullet$ & $\bigcirc$ & $\bigcirc$ & $\bigcirc$ & $\bigcirc$ & $\bigcirc$ & $\diamond$ & $\bigcirc$ & 0 \\
\hline Niveoscincus coventryi & O & O & $\bullet$ & $\bullet$ & $\bigcirc$ & $\bigcirc$ & $\bigcirc$ & $\bullet$ & & $\bullet$ & $\bigcirc$ & 0 \\
\hline $\begin{array}{c}\text { Niveoscincus } \\
\text { metallicus }\end{array}$ & ○ & $\bigcirc$ & $\bigcirc$ & ○ & $\bigcirc$ & $\bullet$ & $\bullet$ & $\bullet$ & & $\bullet$ & $\bigcirc$ & 0 \\
\hline $\begin{array}{l}\text { Proablepharus } \\
\text { kinghorni }\end{array}$ & $\bigcirc$ & 0 & 0 & 0 & 0 & 0 & 0 & 0 & 0 & 0 & 0 & 0 \\
\hline $\begin{array}{l}\text { Pseudemoia } \\
\quad \text { pagenstecheri }\end{array}$ & $\bigcirc$ & 0 & $\bullet$ & 0 & 0 & 0 & 0 & $\bullet$ & 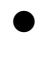 & 0 & $\diamond$ & 0 \\
\hline
\end{tabular}

A single individual per species was tested

- Indicates amplification of a product of comparable size to that amplified from $L$. delicata. $\bigcirc$ Indicates no amplification of any products. $\diamond$ Indicates amplification of a product of a substantially different length from that amplified from $L$. delicata

Lamp4 in the Victoria-Tasmania region due to difficulties in amplifying this locus in all samples (Table 1). No significant LD was detected between any of the locus pairs.

All 12 microsatellite loci were successfully amplified in each of the three invasive populations (New Zealand, Hawaiian Islands, Lord Howe Island; two individuals screened per population). These primers will be used to compare the level of genetic variation between source and introduced populations, and investigate the invasion dynamics of the L. delicata. Cross-species amplification of the loci was assessed in Lampropholis guichenoti and 13 species from other Australian genera within the Eugongylus Group lineage of skinks (Table 2). Amplification success was high, with 1-8 loci successfully amplifying in each species (Table 2), indicating the potential for these loci to be useful in other skink species within the Eugongylus lineage.

Acknowledgments We thank S. Smith and R. Sadlier for providing samples for cross-amplification. S. Chapple, S. van Barneveld and F. Kraus assisted with fieldwork. We thank Genetic Identification Services and the Australian Genome Research Facility for assistance 
in developing the microsatellite library, and genotyping the loci. Fieldwork was completed in accordance with Animal Ethics guidelines (VUW: 2006R12; University of Sydney: L04/3-2007/1/4572; Museum Victoria: 07002), under the appropriate collection permits (Victoria: 10004254; Tasmania: FA07221; LHI: S12249; NZ: AK-20182-FAU). This research was funded by the National Geographic Society (grant to DGC and MBT) and the Australian Research Council (grant to DGC, Project Number DP0771913).

\section{References}

Baker JK (1979) The rainbow skink, Lampropholis delicata, in Hawaii. Pac Sci 33:207-212

Hutchinson MN, Thompson MB, Stewart JR (2005) Lampropholis delicata (delicate skink, rainbow skink). Introduction. Herpetol Rev 36:450-451
Jones KC, Levine KF, Banks JD (2002) Characterization of 11 polymorphic tetranucleotide microsatellites for forensic applications in California elk (Cervus elaphus canadensis). Mol Ecol Notes 2:425-427

Lever C (2003) Naturalized reptiles and amphibians of the world. Oxford University Press, Oxford

Peace J (2004) Distribution, habitat use, breeding and behavioural ecology of rainbow skinks (Lampropholis delicata) in New Zealand. Unpublished MSc Thesis, University of Auckland, New Zealand

Peakall R, Smouse PE (2006) GenAlEx 6: genetic analysis in Excel. Population genetic software for teaching and research. Mol Ecol Notes 6:288-295

Rousset F (2008) GENEPOP'007: a complete re-implementation of the GENEPOP software for Windows and Linux. Mol Ecol Res 8:103-106

Wilson S, Swan G (2008) A complete guide to reptiles of Australia, 2nd edn. Reed New Holland, Sydney 